\title{
REGIONAL SPECIALIZATION IN THE EUROPEAN UNION
}

Roberto Ezcurra

Carlos Gil

Pedro Pascual

D.T.2004/04 


\title{
Regional specialization in the European Union*
}

\author{
Roberto Ezcurra, Carlos Gil and Pedro Pascual ${ }^{\dagger}$ \\ Department of Economics \\ Universidad Pública de Navarra
}

\begin{abstract}
This paper examines productive specialization in the regions of the European Union over the period 1977 to 1999 using the information provided by various methodological instruments. The results obtained reveal a process of convergence in regional productive structures during the twenty-three years considered. This has been due to the behavior of regions with high levels of specialization at the start of the period, whose productive structures have tended to shift towards the European average over time. The analysis carried out also highlights the major role played by regional size, level of development and geographical location in explaining specialization in the European context. Finally, the empirical evidence provided suggests that changes in regional productive structures are closely linked to the evolution of the spatial distribution of per capita income in the European Union.
\end{abstract}

Key words: Specialization, economic activity, regions, European Union.

JEL Code: F15, R11, R12.

${ }^{*}$ The authors wish to acknowledge financial support from MCYT (Project BEC2002-03941) and the Fundación BBVA.

${ }^{\dagger}$ Postal address: Roberto Ezcurra, Department of Economics, Universidad Pública de Navarra, Campus de Arrosadia s/n. 31006 Pamplona (Spain). E-mail address: roberto.ezcurra@unavarra.es. 


\section{Introduction}

In recent years, the issue of territorial imbalances in the European Union has been examined in numerous studies from a variety of different approaches ${ }^{1}$. In this respect it is worth recalling the influence of the sectoral composition of economic activity on regional growth $^{2}$. Changes in regional productive structures, therefore, might contribute either reducing or increasing existing disparities in development terms in a given geographical area.

Taking up this idea, this paper examines productive specialization in the regions of the European Union between 1977 and 1999, paying particular attention to the ways in which this relates to the evolution of the spatial distribution of per capita income.

Issues of this kind are especially relevant within the framework of the integration process currently underway within the European Union. In this respect, the creation of the Single Market and the adoption of a single currency by the majority of the Member States may have resulted in significant changes in regional productive structures. Indeed, growing integration has brought about the increasing removal of trade and economic barriers between the various countries involved. This should, in theory, generate overall gains in efficiency resulting from greater opportunities to exploit scale economies and the advantages offered by different potential locations in terms of elements such as factor endowment, level of skilled labor, or capacity for innovation and adaptation to new technologies ${ }^{3}$. In the present single currency environment, however, convergence or divergence in productive structures will have serious implications on single monetary policy design, since either situation can have a decisive influence on the degree of exposure of the various economies to asymmetric shocks. Nevertheless, economic theory is inconclusive in determining how far integration processes influence on disparities in 
productive structures. The study of the characteristics of productive adjustments that take place as a result of integration agreements is, therefore, of a primarily empirical nature.

Though in the last few years there have emerged several studies dealing with productive specialization patterns within Europe, there are very few regional studies that cover the European Union as a whole ${ }^{4}$. Part of the reason for this is, no doubt, the lack of suitable statistical information ${ }^{5}$. In this respect, our paper represents a break from the existing literature on this subject. The use of data supplied by Cambridge Econometrics has enabled us to work with sectorally disaggregated information relating to 17 productive activities (classification NACE-CLIO R17) for 197 NUTS2 regions over the period 1977-1999, a considerably larger geographical area than that covered in the very few existing works devoted to this issue ${ }^{6}$.

A further contribution of this paper has to do with the methodology it uses to explore the evolution of productive structures in the regions of the European Union. Thus, we have completed the usual approach adopted in this type of studies, based mainly on the calculation of various specialization indices, by adding information yielded by a series of instruments popularized by Quah $(1996 \mathrm{a}, 1997)$ within the framework of the literature on regional per capita income disparities. We have also analyzed the explanatory factors involved in regional specialization by estimating various panel data models.

With respect to the organization of the paper, section 2 , which follows this introduction, contains a brief overview of the theoretical and empirical literature dealing with the subject of the spatial distribution of economic activity. This will provide the frame of reference for our investigation. In sections 3 and 4 , we explore the evolution of regional specialization within the European Union between 1977 and 1999. Section 
5 presents an analysis of the role played by a series of variables in the changing trends in regional productive structures over time. This is followed in section 6 with a study of the relationship between changes in regional specialization and the evolution of per capita income distribution. Finally, section 7 contains the main conclusions.

\section{Frame of reference}

The aim of this section is to offer a brief overview of the literature on the spatial location of economic activity, both from a theoretical and applied perspective.

We will begin our review with a reference to traditional location theory, which began with Von Thünen and continued with Weber, Christaller, Lösch and Isard ${ }^{7}$. These authors attempt to explain the spatial location of an activity using microeconomic models. Subsequent economic theory has not paid much attention to this approach, however, due, in part, to certain limitations inherent in the methodology on which it relies. The justification for individual decision-making processes, for example, is often confusing or even absent. Problems also arise in relation to the definition of market structure (Krugman, 1995).

International trade theories provide an alternative explanation for the spatial location of economic activity. The neoclassical theory of international trade, in particular, considers commercial transactions between countries to be the final result of the differences that exist between them, either in terms of available technology (Ricardo, 1817) or factor endowment [Heckscher (1919), Ohlin (1933)]. These models are developed in an environment of perfect competition, homogenous goods and constant returns to scale. According to these premises, the removal of trade barriers allows each country to specialize in whatever goods it is able to produce more cheaply than the rest (compara- 
tive advantage). Processes of economic integration will therefore increase differences in productive structures across participating countries and foment interindustrial trade.

The neoclassical theory of international trade readily accounts for the transactions that take place between countries with different factor endowments, as for example in the case of exchanges between developed and developing countries. There are, however, a great number of empirical studies that have revealed the existence of certain features of international trade that are difficult to reconcile with neoclassical theory ${ }^{8}$. Nowadays, therefore, most commercial transactions take place between industrialized countries with similar factor endowments. A growing percentage of this trade, moreover, is intraindustrial $^{9}$.

In an attempt to explain phenomena such as these, there arose in the early eighties what has been termed as the "new international trade theory". This departed from the underlying premises of the neoclassical theory and replaced them with imperfect competition models which admit the existence of economies of scale, the market power of firms and horizontal differentiation of products (Krugman, 1979). Increasing returns are precisely what induce firms to concentrate their production geographically, so that each plant can serve the greatest possible number of markets, a situation which tends to increase the number of commercial exchanges. This, in turn, requires firms to differentiate their products from those of their competitors in order to maintain a certain level of market power, which is the reason for intraindustrial trade ${ }^{10}$. According to the assumptions of these models, the removal of trade barriers following the signing of economic integration agreements will allow fuller exploitation of scale economies. In contrast to the outcome predicted by neoclassical theory, however, there is no reason why there should be any significant changes in productive structures. In fact, in this new setting, 
countries end up with each sector specializing in the production of different varieties of the same product, thereby removing the need to shift productive factors and resources from one activity to another ${ }^{11}$.

The new theory of international trade is based on the assumption that there exist exogenous differences in market size. The endogenization of this variable gave rise from the early nineties onwards to a series of models that make up what has come to be known as the "new economic geography". Generally speaking, the new economic geography can be said to represent a new approach in the study of the spatial location of economic activity, in which increasing returns to scale, agglomeration economies and imperfect competition play a major role. Though restrictions in the length of this paper prevent us from offering a detailed analysis of these contributions ${ }^{12}$, we must stress that, as far as the spatial distribution of production is concerned, their conclusions are not definitive, and rely critically on the underlying assumptions. On the one hand, economies of scale encourage the geographical concentration of economic activity (Krugman, 1991b). However, the final result, as indicated in Puga (1999), depends crucially on the level of transport costs and particularly on the degree of labor mobility.

To sum up, we might point out that the various theoretical approaches examined do not provide a definitive basis on which to determine the pattern and the explanatory factors involved in the spatial location of economic activity. The validity of each of these approaches must therefore be submitted to empirical testing ${ }^{13}$.

To this end, we now present a brief review of the results obtained in a series of empirical studies dealing with productive specialization in the European context ${ }^{14}$. In this respect, a prior consideration is worth bearing in mind, in order to obtain an initial idea of the current state of the issue. Analysis at European Union level differ widely one 
from the other, depending on the spatial and temporal scales, data bases and statistical instruments used in each case (Combes and Overman, 2003). All of this raises major problems when it comes to comparing the results obtained.

We could begin by mentioning a number of papers dealing with the analysis of spatial distribution of the industrial sector in a set of European countries ${ }^{15}$. These works appear to coincide in finding that increasing economic integration has been accompanied by greater differentiation in regional productive structures and stronger geographic concentration of production.

Studies adopting a regional approach are far fewer, however. Though there are some regional analysis for a certain member States ${ }^{16}$, relatively few works have been undertaken using the regions of the entire European Union as their unit of reference. As we pointed out in the introduction to this article, this is mainly due to the lack of availability of the required statistical data at this level of geographical disaggregation.

Nevertheless, Molle (1996) describes changes in the sectoral structure of employment in 96 NUTS1 and NUTS2 regions between 1950 and 1990. In contrast to the studies carried out for a set of countries, this author bases his analysis on data for the whole range of economic activity, including the agricultural and service sectors. The results obtained show that regional productive structures have tended to converge over time. The study reveals the most highly specialized regions in 1990 to be those of the European periphery. In addition, indices of the geographical concentration of employment are found to have decreased in the majority of the 17 sectors considered.

At the same level of sectoral disaggregation, Hallet (2002) addresses the issue of the spatial distribution of economic activities in 119 NUTS1 and NUTS2 regions between 1980 and 1995. In this case, the variable used is value added, instead of employment. 
The resulting analysis shows that regional specialization has diminished slightly, in aggregate terms, over the period considered. This is a result of the behavior pattern of 85 of the regions included, the productive structures of which have tended to shift towards the European average. The geographic concentration of industry, meanwhile, has undergone little significant change during the time period contemplated. Agriculture and its associated industries are the activities with the highest levels of geographical dispersion, with various sectors dedicated to the production of traded goods appearing at the other end of the scale.

\section{Regional specialization}

In this section we will study the main characteristics of regional specialization in the European regions from 1977 to 1999. This will enable us to illustrate the main changes that have occurred during that period in which substantial progress was made in the ongoing process of economic integration.

Questions of this type tend to be analyzed in the literature by means of the calculation of various (absolute and relative) measures that allow the phenomenon under analysis to be synthesized in an unique value ${ }^{17}$. According to this procedure, and in order to find out the level of specialization of the various regions considered, we have calculated initially for each of them the following index based on Krugman (1991a):

$$
S P E_{i}^{K}=\sum_{j=1}^{m}\left|q_{i j}-\overline{q_{i j}}\right|
$$

with $q_{i j}=\frac{X_{i j}}{\sum_{j=1}^{m} X_{i j}}$ and $\overline{q_{i j}}=\frac{\sum_{k \neq i}^{n} X_{k j}}{\sum_{k \neq i}^{n} \sum_{j=1}^{m} X_{k j}}$, where $X_{i j}$ is the value added at market prices of region $i$ in sector $j$, such that $i=1,2, \ldots, n$ and $j=1,2, \ldots, m . S P E_{i}^{K}$ can be understood as a measure of regional divergence, in that it compares the productive structure 
of a given region with that of the others. Indeed, if $q_{i j}=\overline{q_{i j}}$, the value of the index would logically be zero. For a region with a sectoral structure completely different from that of the rest of the European Union, however, we would have $S P E_{i}^{K}=2$. Likewise, from expression (1) it is possible to obtain an aggregate measure of specialization for the whole of the European Union:

$$
E S P^{K}=\sum_{i=1}^{n} \omega_{i} S P E_{i}^{K}
$$

where $\omega_{i}$ is the weighting assigned to region $i$ according to its economic or demographic size, with $\sum_{i=1}^{n} \omega_{i}=1$.

\section{[INSERT FIGURE 1 AROUND HERE]}

Figure 1 presents the results obtained from the calculation of $E S P^{K}$ for the period 1977-1999, taking different weightings based on the income and population shares of each region. To check for possible significant differences in changes in regional specialization over time, we have normalized the different measures by assigning a value of 100 to the level at the first year of the period. According to the results obtained, regional specialization has decreased in the European context throughout the study period. Indeed, over the twenty-three years considered, the value of $E S P^{K}$ has diminished by between $9 \%$ and $1 \%$, depending on the weighting applied in its calculation ${ }^{18}$. The degree of decline in productive specialization lessens when the various regions are weighted according to economic and demographic criteria. This suggests that, generally speaking, the reduction in $E S P^{K}$ observed over time has been relatively greater in smaller regions ${ }^{19}$.

It is also worth noting that there exist two clearly defined stages in the evolution of $E S P^{K}$. During the late seventies and the eighties, there was a gradual decrease in 
regional specialization in the European Union, the lowest level being reached in 1990. Nevertheless, this trend changed during the following decade. Indeed, the index values increased throughout the nineties with a steep rise from 1995 onward. In fact, there was such a strong increase in specialization in those years that the indicator weighted by regional income shares almost made up for the reduction registered in the previous period. Therefore, the advances experienced by the European integration process have coincided with an increase in the differences in the regional productive structures ${ }^{20}$. This result has particular relevance in the current context of the single currency. Indeed, it suggests that during the late nineties the European regions have become more vulnerable to asymmetric shocks, a fact which might have important implications for the single monetary policy ${ }^{21}$.

However, the evolution of regional specialization is due to adjustment processes of different nature, and it would, therefore, be reasonable to expect this to be reflected in the spatial context in various ways. In an attempt to identify some kind of regional behavior pattern, we will now consider the initial level of specialization and the variation in $E S P^{K}$ during the study period. A first graphical analysis of this question suggests the existence of a marked tendency towards convergence in regional specialization levels between 1977 and 1999 (Figure 2). In other words, during these twenty-three years there has been an inverse relationship between variations in regional specialization and the initial level of $E S P^{K 22}$

\section{[INSERT FIGURE 2 AROUND HERE]}

Detailed analysis of Figure 2 reveals the existence of a national effect. Indeed, though the various regions have followed different patterns, as might be expected, the fact of their belonging to a particular country makes them appear in Figure 2 quite closely 
grouped together, occupying a distinct position in relation to the rest. Though there are some obvious exceptions, in overall terms, the data confirm the described tendency. We can therefore report that regions belonging to the same member State are characterized not only by similar productive structures when compared to the rest of the European Union in the first year of the study period, but also by similar patterns of behavior with respect to productive specialization between 1977 and 1999 .

There are some specific cases in which this is particularly obvious. The Greek regions, for example, appear in the lower right hand part of the figure. These regions register the highest values of the specialization index in the year 1977, as a result of the important weight of agriculture in these economies in comparison to the rest of the European Union. Nevertheless, over the twenty-three years considered, the level of regional specialization has fallen in the case of the Greek regions, with the result that their productive structure has tended toward convergence with the European average. The situation in the German regions, meanwhile, is quite the opposite. These regions are to be found mainly in the upper left hand area of the figure, since they began the period with productive structures relatively similar to the European average. In spite of their initial situation, however, several of these regions have registered the highest increases in $E S P^{K}$ over the study period.

\section{The dynamics of regional specialization}

As is usual in the literature, in the previous section we have examined the level and the evolution of productive specialization in the European regions between 1977 and 1999 according to the information provided by $S P E_{i}^{K}$. However, this approach presents a major limitation in that it does not capture a series of potentially interesting features 
of the dynamics of the specialization index distribution. In particular, the analysis carried out so far neglects to consider, for example, the possible existence of distinct clusters of regions with a similar productive structure that set them apart from the rest of the population. The conventional approach also fails to inform about the fact that the various regions may shift their relative positions in terms of specialization over the study period. To overcome these problems, in this paper we will examine these questions by means of the use of various econometric instruments proposed by Quah (1996a, 1997) in the context of the literature on spatial disparities in per capita income.

Adopting this strategy, we will begin by estimating the density functions corresponding to the specialization index distribution. Following common practice, we have used non-parametric estimation techniques, thus avoiding the need to specify any particular functional form beforehand. This kind of approach undoubtedly offers major advantages in the present context, given that parametric approximations are lacking in generality and flexibility.

\section{[INSERT FIGURE 3 AROUND HERE]}

Figure 3 shows the density functions, both simple and weighted by income shares, of the regional distribution of $S P E_{i}^{K 23}$. The values of the specialization index (multiplied by 100) are plotted on the $\mathrm{x}$ axis and the distribution of probability associated on the $\mathrm{y}$ axis. Estimates are based on calculations using gaussian kernel functions. Likewise, the smoothing parameter value is determined in each case following Silverman $(1986)^{24}$.

\section{[INSERT FIGURE 3 AROUND HERE]}

The results obtained reveal significant differences in the external shape of the densities estimated, depending on whether or not weightings are included in the analysis. 
Thus, when each observation is weighted by its income share, there is an increase in the probability mass concentrated around low and medium values of the index, as a consequence of the weight reduction experienced by the right-hand tail of the distribution. This fact allows us to play down, within the European economy as a whole, the quantitative importance of regions with values of the specialization index at the upper extreme of the distribution. Figure 3 also shows that the probability mass shifted gradually towards the left until 1990. This suggests the existence of a process of homogenization in regional productive structures over this period. Nevertheless, there was a reversal of this trend in the nineties. It is worth noting that these results confirm the conclusions reached in the previous section about the evolution of $S P E_{i}^{K}$ in the European regions throughout the period between 1977 and 1999.

Likewise, the various density functions estimated in Figure 3 are characterized in general by having a single mode where most of the probability mass is concentrated. In contrast to this general tendency, however, half way through the eighties, further local maxima appear at the upper extreme of the distribution, grouping regions with relatively high levels of specialization. Nevertheless, in the years that follow, there is a change in this situation, revealing that the regions in question managed to bring their productive structures with the European average. However, at the end of the nineties, there are signs to suggest the possible formation of a new pole, again grouping regions with values of the specialization index above the average.

The density functions estimated in Figure 3 give a first impression of the external shape of the distribution for each year considered. This type of analysis, however, is based on a series of cross-sections of the distribution examined, and does not, therefore, take into account that the different economies may shift their relative positions 
in terms of specialization over time. To address this shortcoming and to complete the results obtained so far, we will now take a look at the regional mobility observed in the distribution of the specialization index between 1977 and 1999.

Most of the studies that have addressed this issue in the context of the literature dedicated to the study of spatial disparities in per capita income are based on the information provided by discrete transition matrices, obtained by dividing the distribution into a series of exhaustive and mutually exclusive $\operatorname{classes}^{25}$. This approach entails a problem, however, since the results it yields are sensitive to the way in which the original distribution is divided up. In fact, since there is no procedure for determining the optimum number of classes in each case, the researcher's choice must necessarily be arbitrary. To address this problem, Quah (1996a, 1997) suggests substituting the transition matrix with a stochastic kernel that reflects the probabilities of transition between a hypothetically infinite number of classes, reducing their size infinitesimally. According to Quah (1996a, 1997), the stochastic kernel can be reached by estimating the density function of the distribution over a given period, $t+k$, conditioned by the values corresponding to a previous period, $t$. In other words, the joint density function at moments $t$ and $t+k$ is estimated and then divided by the implicit marginal distribution in order to obtain the corresponding conditional probabilities.

Before discussing the results obtained when we apply this instrument to the analysis of distribution dynamics, some clarification of the methodology is required. Specifically, gaussian kernel functions are used in all cases, and the smoothing parameter has been selected again following Silverman $(1986)^{26}$.

\section{[INSERT FIGURE 4 AROUND HERE]}

Figure 4 shows the stochastic kernel estimated from the regional distribution of the 
specialization index for a period of twenty-three years $(t=1977$ and $t+k=1999)$. This three-dimensional graph can be interpreted as a transition matrix with an infinite number of classes, that informs about the probabilities associated with each pair of values in the first and last years of the study period. In other words, the stochastic kernel gives us, as does a discrete transition matrix, the probability distribution of 1999 $S P E_{i}^{K}$ for regions with a given value of the index in 1977. High levels of probability are represented by the peaks on the graph. Thus, if the probability mass is concentrated around the main diagonal, the intradistributional dynamics are characterized by a high level of persistence in the relative positions of the regions over time and, therefore, low mobility. If, on the other hand, the density is located mainly on the opposite diagonal to the main diagonal, this would indicate some regions overtaking others in the ranking generated by the specialization index. Finally, the probability mass could, in theory, accumulate parallel to the $t$ axis. This would reflect the convergence of regional productive structures around a given value of $S P E_{i}^{K}$. In order to aid interpretation of the results, Figure 4 also includes a contour plot on which the lines connect points at the same height on the three-dimensional kernel.

According to Figure 4, the probability mass is concentrated around the main diagonal. As we know, this indicates the existence of a low level of mobility in the distribution of the $S P E_{i}^{K}$, so the European regions tend generally to maintain their relative positions in terms of specialization throughout the twenty-three years considered. Nevertheless, it is also possible to appreciate a notable turn in the right-hand side of the distribution. This would seem to suggest that the reduction observed in regional specialization between 1977 and 1999 has been due mainly to the dynamics experienced by those regions at the upper extreme of the distribution, whose productive structures have tended to 
shift towards the European average.

In order to complete our study, we have estimated the corresponding ergodic distribution by iteration of the stochastic kernel until the convergence of the process is reached $^{27}$. Given that this is, by definition, a continuous distribution, it can be represented graphically (Figure 5). As we can see, the ergodic distribution is characterized by having a single mode, which indicates that clusters of regions with similar levels of specialization are unlikely in the long term. The information provided by Figure 5 also suggests that the process of convergence in the regional productive structures observed over the study period will not continue indefinitely ${ }^{28}$. In this type of scenario, therefore, territorial imbalances in per capita income will be directly related to the sectoral composition of activity and will not be exclusively function of those aggregate factors that have an uniform impact on productivity in all activities.

\section{[INSERT FIGURE 5 AROUND HERE]}

\section{Explanatory factors of regional specialization}

The various methodological options used up to this point give no insight into the determinants of the evolution of productive structures in the European context. For this reason and in order to complete the results obtained so far, in this section we will analyze the factors explaining the evolution of regional specialization in the European Union between 1977 and 1999.

To achieve this objective, we have considered a series of variables on which we have regional information for the twenty-three years between 1977 and 1999. In this way we intend to make use of the econometric advantages to be gained from using panel data.

According to this strategy, therefore, we begin by contemplating the possibility that 
the size of the regions may be related to their level of productive specialization ${ }^{29}$. It appears reasonable, a priori, to assume the existence of an inverse relationship between these two variables. In fact, larger regions are usually characterized by a more heterogeneous population and variation in physical factors such as the endowment of natural resources and geographical and climatic features, which, ceteris paribus, should be reflected in lower levels of specialization than in smaller regions. In contrast to this idea, various contributions made within the context of the "new economic geography" have underlined the important role played by agglomeration economies when it comes to explain the spatial distribution of economic activity ${ }^{30}$. While agglomeration economies may, on the one hand, attract different industries to larger regions, thus promoting diversification in the productive structure, there may, at the same time, be specific agglomeration economies in certain industries, which would tend to increase the level of specialization in larger regions. To weigh up the relative importance of each of these arguments in the European case, we have opted to include regional population, $P O P_{i t}$, in our model as a measure of regional size.

It is also worth analyzing the nature of the relationship between the density of population in a region, $D E N S_{i t}$, and its level of productive specialization. The argument put forward by Krugman (1991a) in this respect is that transport costs are a decisive factor in industrial location. Thus, industries that have to support high transport costs will tend to locate mainly in densely populated regions. This could have a detrimental effect on such areas, however, since excessive agglomeration could generate congestion costs. In such a situation, industries with low transport costs might, in theory, be attracted to less densely populated regions. From the theoretical point of view, therefore, it remains unclear whether specialization in a region increases or decreases in line with 
the density of its population.

We have also examined the role played by the level of economic development in determining changes in regional specialization by incorporating regional per capita income, $G V A p c_{i t}$, and the square of regional per capita income, $G V A p c_{i t}^{2}$, as explanatory variables in the model. The inclusion of the latter enables us to test the hypothesis put forward by Imbs and Wacziarg (2003) for the European case. These authors have designed a model in which productive specialization falls initially and subsequently rises with the increase in development levels ${ }^{31}$.

There is wide consensus, meanwhile, at least from the theoretical perspective, regarding the impact of market proximity on decisions concerning industrial location ${ }^{32}$. Therefore, since there may be a relationship between the geographical situation of a region and its level of productive specialization, we have opted to differentiate the regions considered in our analysis according to their spatial location. For this we have defined different dummy variables $\left(C E N T R A L_{i}, N O R T H_{i}\right.$ and $\left.S O U T H_{i}\right)$ derived from an alternative classification of the European regions that allows us to introduce new slant on the traditional North-South distinction. Thus, following Keeble et al. (1988) and Copus (1999), we have distinguished among central, intermediate and peripheral regions. Later, in a second stage, we have divided the peripheral regions into two additional groups: North periphery and South periphery (Map A1) $)^{33}$.

Therefore, the model finally proposed to explain regional specialization in the European Union between 1977 and 1999 can be written as:

$$
\begin{aligned}
S P E_{i t}^{K}= & \beta_{0}+\beta_{1} \log P O P_{i t}+\beta_{2} \log D E N S_{i t}+\beta_{3} \log G V A p c_{i t}+ \\
& +\beta_{4} \log (\log G V A p c)_{i t}^{2}+\beta_{5} C E N T R A L_{i}+\beta_{6} N O R T H_{i}+
\end{aligned}
$$




$$
+\beta_{7} \mathrm{SOUTH}_{i}+u_{i t}
$$

The results obtained, shown in Table 1, indicate that the level of specialization decreases as the regional size grows ${ }^{34}$. This highlights the fact that analyzes that approach the study of productive specialization in a given geographical context may be sensitive to the level of territorial disaggregation considered. Likewise, the density of the population would in theory have a positive effect on regional specialization, which would suggest that the productive structures of the more densely populated European regions would tend to deviate from the average.

\section{[INSERT TABLE 1 AROUND HERE]}

Our findings indicate that, with advances in regional development processes, the level of productive specialization tends to decrease initially and increase in later stages. Regional specialization in the European Union over the period considered, therefore, appears to adopt a U-shaped pattern, thus confirming the hypotheses put forward by Imbs and Wacziarg (2003).

The geographical location of European regions, meanwhile, is closely related to their degree of specialization. The Northern and Southern peripheral regions of the European Union do in fact exhibit relatively high levels of specialization. In other words, the further away from the core of the Union a region is, the more its productive structure deviates from the average.

To complete the results obtained so far, we have opted to include national dummy variables in the model ${ }^{35}$. As we can see in Table 1 , this improves the explanatory power of the model estimated previously. National dummy variables turn out to be statistically significant in most cases, moreover. This fact can be interpreted as a further indication 
of the relevance of the spatial component in explaining the level of regional specialization observed within the European context over the period considered. The only noteworthy difference from the results discussed earlier is in connection with the variable $D E N S_{i t}$. In fact, when the national component is introduced into the analysis, the population density appears to have a negative effect on the dependent variable. This raises certain doubts as to the possible effect of $D E N S_{i t}$ on regional specialization, and highlights the need to investigate more deeply into the relationship between these two variables in the European context.

Finally, in order to check the robustness of our conclusions, we have considered the possibility of replacing $S P E_{i t}^{K}$ with a new measure of regional specialization as the dependent variable. According to this idea, we have calculated the following index for each of the regions considered:

$$
S P E_{i}^{(2)}=\sum_{j=1}^{m}\left(q_{i j}-\overline{q_{i j}}\right)^{2}
$$

the values of which lie within the interval $[0,2]$. It should be noted that, in comparison to $S P E_{i}^{K}$, in the calculation of this new measure of specialization greater weight is attached to regions whose productive structures deviate further in relative terms from the European average ${ }^{36}$. The results, which are presented in columns 3 and 4 of Table 1 are very similar to those discussed previously, though the goodness of fit scores are considerably lower. Basically, the main difference is that, in this case, the variable $D E N S_{i t}$ is not statistically significant in the model estimated without national dummy variables.

However, the analysis carried out so far highlights, among other details, the importance of geographical location in explaining the level of regional specialization observed in the European Union over the study period. This suggests that regional specializa- 
tion is not randomly distributed in space, the likelihood being that physically adjacent regions will tend to have similar productive structures. To study this issue further, we will take a closer look at the relevance of the spatial element in the dynamics of regional specialization.

For this purpose, following Quah (1996b), we have constructed a conditioned distribution, obtained by normalizing the specialization level of each region measured by $S P E_{i t}^{K}$, according to the average productive structure of the physically adjacent regions ${ }^{37}$. This conditioned distribution may be intuitively interpreted as that part of the original distribution that remains unexplained by the various factors relating to the spatial location of the regions considered. For a more precise understanding of this idea, let us imagine a situation in which the spatial dimension has no impact at all on the distribution dynamics of $S P E_{i t}^{K}$, so that regions that are more (less) specialized in relation to the European average will also be more (less) specialized than their neighboring regions. In this hypothetical scenario, the original distribution would coincide with the conditioned distribution. If, on the other hand, the spatial variable plays a significant role, we might expect more (less) specialized regions to register a value of the specialization index similar to the average of $S P E_{i t}^{K}$ of the regions with which they are grouped according to spatial criteria.

The proposal made by Quah (1996b) is to analyze these issues by estimating various transition matrices. Nevertheless, as we already know, this approach entails some problems relating to the fact that the researcher needs to determine arbitrarily the number of classes into which the various regions should be grouped initially. To overcome the problems involved in using discrete transition matrices, we have opted in this paper to use stochastic kernels and contour plots instead ${ }^{38}$. 
Before going on to discuss the outcomes obtained, it might be worth clarifying a few points relating to the interpretation of stochastic kernels and contour plots in this context. Within this framework, these instruments provide information concerning the probabilities of transition between the original distribution and the conditioned distribution, and not between two moments of time as in the previous case. Thus, if the spatial dimension does not help to explain the distribution dynamics, the probability mass should cluster around the main diagonal ${ }^{39}$. If, on the other hand, the space is determinant in explaining the evolution of the distribution analyzed, the density will tend to cluster parallel to the axis corresponding to the original distribution and around the average.

\section{[INSERT TABLE 6 AROUND HERE]}

Figure 6 reports the results obtained when these instruments are used to examine the impact of the spatial dimension on the distribution dynamics of regional specialization in the European Union over the study period. To construct the stochastic kernel and the associated contour plot, we have considered information on all twenty-three years between 1977 and 1999. In addition, to facilitate comparisons, the two distributions have been normalized by the European average. The results obtained clearly reveal the important role played by the spatial component in this context. However, detailed observation of Figure 6 enables us to qualify this conclusion somewhat. Specifically, the spatial component certainly seems to be more relevant among regions with high values of the specialization index. Indeed, at the lower extreme of the distribution it is possible to see how the probability mass is concentrated around the main diagonal. This fact indicates that regional specialization tends to be less closely related to the productive structure of the neighboring regions in areas with low values of $S P E_{i t}^{K}$. Therefore, this 
suggests that in the European context, save exceptions, the regions whose productive structures deviate from the average exhibit a higher degree of spatial concentration than regions with low values of the specialization index.

\section{Regional specialization and per capita income distribu- tion}

In the previous section we have examined some of the explanatory factors of regional specialization in the European Union. Nevertheless, it is important to note that, according to Krugman (1991a), variations in the productive structures and the geographic concentration of economic activity influence aggregate growth and, therefore, the spatial distribution of per capita income, so they may either mitigate or aggravate existing disparities in a given geographical area. Taking into account this idea and in order to complete the results obtained so far, in this section we will perform a preliminary analysis of the relationship between the changes in regional specialization and the evolution of territorial imbalances in per capita income observed in the European Union between 1977 and 1999. Specifically, we will investigate to what extent the specialization indices calculated previously differ in their behavior with respect to a number of measures of inequality and polarization associated with the regional distribution of per capita income in the European context.

Bearing in mind that the conclusions to be drawn from the assessment of the inequality of a distribution may vary, at times significantly, according to the indices that are used, we have opted to include various inequality measures in our analysis. Specifically, we have selected for this purpose the Gini index, $G(x)$, the two measures introduced 
by Theil (1967), $T(0)$ and $T(1)$, and the Atkinson's normative index, $A(\varepsilon)$, for different values of the inequality aversion parameter, $\varepsilon^{40}$. It is worth noting, however, that, in contrast to traditional practice in convergence analysis, these measures have been calculated taking into account the differences in population across the European regions ${ }^{41}$.

Nevertheless, conventional inequality measures are of no use when trying to distinguish whether the different regions are clustered around the average of the distribution or around two or more separate poles. For this reason, we have calculated the polarization measure proposed by Esteban et al. (1999), $P(\alpha, \beta)$, after dividing the various regions into two and three groups according to the methodology of Davies and Shorrocks (1989). In order to check the robustness of our conclusions, we have considered in our calculation different values of the parameter $\alpha$ of sensitivity to polarization, while we have assigned the same importance as in Esteban et al. (1999) to internal cohesion within the various groups considered, so $\beta=1^{42}$.

\section{[INSERT TABLE 2 AROUND HERE]}

Table 2 shows the correlation coefficients between specialization indices and the various measures of inequality and polarization estimated for the European Union regional per capita income distribution. All the values obtained are positive and statistically significant, so there exists a considerable degree of association between the evolution of inequality and regional polarization and the changes experienced by productive specialization throughout the twenty-three years considered. Nevertheless, it is interesting to note that in the case of Atkinson's index, the magnitude of the coefficients decreases with increases in the value of the inequality aversion parameter. In addition, Table 2 indicates that productive specialization is more closely correlated with regional polarization than with regional inequality. 
Therefore, the results obtained reveal that changes in regional specialization are closely linked to the evolution of regional per capita income in the European Union over the study period. This fact suggests that the increase in regional specialization detected during the nineties in previous sections, may have helped to explain the absence of convergence in regional development levels and the maintenance of the degree of polarization of regional per capita income observed over this period in the literature ${ }^{43}$. In any case, these results highlight the need for further investigation, both from a theoretical and empirical perspective, into the nature of the relationship between specialization, inequality and regional polarization.

\section{Conclusions}

In this paper we have examined productive specialization in the regions of the European Union over the period 1977 to 1999.

The results obtained, by means of the application of different methodological instruments, show a decrease in regional specialization in aggregate terms throughout the twenty-three years considered, relatively greater reduction taking place in small regions. This evolution has been due to the behavior of regions with high levels of specialization at the start of the period, whose productive structures have tended to shift towards the European average over time. Nevertheless, the process of convergence in the levels of productive specialization detected between 1977 and 1999 will not continue indefinitely, so that, in the future, regional disparities will continue to be directly related to the sectoral composition of activity.

The reduction of regional specialization observed has not been uniform throughout the whole period, however. In fact, during the late seventies and the eighties, regional 
specialization decreased gradually. Nevertheless, this trend changed during the nineties, so the advances in the European integration process have coincided with an increase in the differences in the regional productive structures.

In order to complete the analysis, we have examined the explanatory factors involved in regional specialization by estimating various panel data models. The empirical evidence provided suggests the existence of an inverse relationship between the level of specialization observed and regional size. In addition, the results obtained indicate that productive specialization falls initially and subsequently rises with the increase in development levels, thus confirming in the European case the hypothesis put forward by Imbs and Wacziarg (2003).

Likewise, our estimations highlight the important role played by the spatial dimension in the regional specialization distribution in the European context during the period considered. Specifically, the further away from the core of the Union a region is, the more its productive structure deviates from the average. Moreover, regions with high levels of specialization have a greater tendency to cluster geographically than regions whose productive structures are similar to the European average.

Finally, our findings suggest that the changes in productive specialization are closely linked to the evolution of the distribution of per capita income in the regions of the European Union.

\section{Notes}

\footnotetext{
${ }^{1}$ An overview of the main results arising from this literature can be found in Armstrong (2002) or Terrasi (2002).

${ }^{2}$ This question has been stressed in the European context by Paci (1997), European Commission (1999) or Gil et al. (2002).

${ }^{3}$ For a more detailed analysis, see Midelfart-Knarvik and Overman (2002).

${ }^{4} \mathrm{As}$ exceptions to this general trend, it is worth mentioning the contributions made by Molle (1996) and Hallet (2002).
} 
${ }^{5}$ Combes and Overman (2003) describe in some detail the main available sources of statistics relating to this issue at European level.

${ }^{6}$ Nevertheless, incomplete data series have obliged us to exclude from our analysis the countries newly incorporated into the European Union in May of 2004, the Länder of former East Germany, the French overseas departments and Spain's North African territories. A complete list of the regions covered by this study is included in the appendix.

${ }^{7} \mathrm{~A}$ detailed account of the main contributions of these authors can be found, for example, in Fujita et al. (1999).

8 See Balassa (1966) or Grubel and Lloyd (1975).

${ }^{9}$ See Greenway and Hine (1991) or Brülhart and Hine (1999).

${ }^{10}$ For this it is necessary also to assume that consumer preferences are not fully matched by the homeproduced varieties of the product in question.

${ }^{11}$ See Krugman (1980, 1981).

${ }^{12}$ Readers interested in this literature may consult the reviews of Ottaviano and Puga (1998) and Fujita and Thisse (2002).

${ }^{13}$ See Brülhart (1998a).

14 Though reasons of space oblige us to exclude any references to other geographical areas, interested readers may consult the panoramic studies of Holmes and Stevens (2003) on North America, and Fujita et al. (2003) on Asia.

${ }^{15}$ See, for example, Brülhart (1998b), Haaland et al. (1998), Amiti (1999) or Midelfart-Knarvik et al. (2000).

16 Among them we would include the contributions of Paluzie et al. (2001) for the case of Spain or Devereux et al. (2002) for the United Kingdom.

${ }^{17}$ None of these measures can be said to be optimal, however. For further details about this question, see Combes and Overman (2003).

${ }^{18}$ A similar result was obtained by Hallet (2002) for a smaller geographical area and shorter time period than considered in our paper.

19 We have performed a further analysis, differentiating in terms of the date of accession of each member State to the European Union. Nevertheless, according to the results obtained, this fact does not contribute to explain the evolution of regional specialization in the European context.

${ }^{20}$ In order to check the robustness of these results, we have estimated a panel data model where regional specialization is explained by a quadratic function of time. Specifically,

$$
S P E_{i t}^{K}=\beta_{0}+\beta_{1} T_{i t}+\beta_{1} T_{i t}^{2}+u_{i t}
$$

As we can see in Table A2, the explaining variables are statistically significant. In addition, their signs confirm the conclusions obtained previously.

${ }^{21}$ Pons and Tirado (2003) present evidence that supports the existence of an inverse relationship between productive specialization and synchrony in the economic cycle of the European regions.

${ }^{22}$ The estimation of the corresponding regression confirms this result. Indeed,

$$
\Delta S P E_{i}^{K}=0.1365-0.4509 E S P_{i}^{K}(1977)
$$

where $\operatorname{ESP}_{i}^{K}(1977)$ is statistically significant $(t=-17.58)$. Likewise, $\bar{R}^{2}=0.5885$.

23 Though density functions were estimated for each year of the time period considered, because of shortage of space, only those for 1977, 1980, 1985, 1990, 1995 and 1999 are shown. The rest are available from the authors upon request.

${ }^{24}$ See Silverman (1986), p. 47.

${ }^{25}$ See, for example, López-Bazo et al. (1999) or Cuadrado et al. (2002).

${ }^{26}$ The estimates have been carried out in Gauss, using the code proposed by Shuetrim (1999) to obtain the bivariate density function.

${ }^{27}$ The intuitive idea that underlies this exercise is the same as that applied to obtain a limit solution in the case of transition matrices with a finite number of classes.

${ }^{28}$ It must be noted that comparisons between Figure 5 and the density functions estimated previously must be made only in terms of the shape of the distribution, since there is no point in comparing the density levels that appear on the vertical axis.

${ }^{29}$ This issue is addressed in various empirical studies dating back at least as far as Ullman and Dacey (1960). See also Dewhurst and McCann (2003).

${ }^{30}$ See Krugman (1991a), Venables (1996) or Fujita et al. (1999). 
31 Acemoglu and Zilibotti (1999) provide theoretic support for the existence of a decreasing trend in the level of specialization during the early stages of development. See also the empirical evidence for the United States provided by Kim (1995).

32 This idea already appeared in Harris (1954) which dealt with the location of the US manufacturing industry.

${ }^{33}$ In addition to geographical criteria, Keeble et al. (1988) and Copus (1999) also consider to form the groups different economic variables related to the degree of periphericity of the European regions. According to this classification, we have 60 central regions, 68 intermediate regions, 22 northern peripheral regions and 47 southern peripheral regions. In population terms, the above groups account respectively for $33 \%, 36 \%, 8 \%$ and $23 \%$ of the total European population in 1999 .

${ }^{34}$ Dewhurst and McCann (2003) obtain a similar result for the UK using regional employment data.

${ }^{35}$ In this case the spatial variables were removed because of their high correlation with several of the national dummy variables.

${ }^{36}$ The appendix includes information about the evolution of regional specialization in the European Union between 1977 and 1999 according to $S P E_{i}^{(2)}$.

${ }^{37}$ Obviously, we could have considered various alternative normalizations incorporating additional related factors, such as the length of interregional borders or even the physical characteristics of the terrain close to the borders.

${ }^{38}$ These instruments are used by Overman and Puga (2002) to investigate the origin of the disparities in regional unemployment rates in the European Union.

${ }^{39}$ In the discrete case, the corresponding transition matrix ought to coincide with the identity matrix.

${ }^{40}$ All the indices selected are independent of scale and size of population and they all fulfill the PigouDalton transfer principle. Chakravarty (1990) and Cowell (1995), among others, make a detailed analysis of these and other normative properties that should be satisfied by an inequality index.

${ }^{41}$ See Armstrong (1995), Sala-i-Martin (1996) or Rodríguez-Pose (1999), among many others.

${ }^{42}$ For further details, see Esteban et al. (1999).

${ }^{43}$ See Puga $(1999,2002)$ or Midelfart-Knarvik et al. (2000), among others. 


\section{References}

Acemoglu, D. and F. Zilibotti (1999). Information Accumulation in Development. Journal of Economic Growth 4: 5-38.

Aміті, M. (1999). Specialisation patterns in Europe. Weltwirtschaftliches 135: 1-21.

Armstrong, H. (1995). Convergence among Regions of the European Union 1950-1990. Papers in Regional Science 74: 125-142.

Armstrong, H. (2002). European Union Regional Policy: Reconciling the Convergence and Evaluation Evidence. In J. R. Cuadrado and M. Parellada (eds.), Regional Convergence in the European Union, Facts, Prospects and Policies. Berlin: Springer-Verlag.

BAlAssa, B. (1966). Tariff reductions and trade in manufactures among the industrial countries. American Economic Review 56: 466-473.

Brülhart, M. (1998a). Economic Geography, Industry Location and Trade: The Evidence. The World Economy 21: 775-801.

Brülhart, M. (1998b). Trading Places: Industrial Specialisation in the European Union. Journal of Common Market Studies 36: 319-346.

BRÜLhaRT, M. and R. Hine (1999). Intra-industry trade and adjustment. The European experience. London: Macmillan.

Chakravarty, S. R. (1990). Ethical Social Index Numbers. Berlin: Springer Verlag.

Combes, $\mathrm{P}$ and H. Overman (2003). The spatial distribution of economic activities in the Eurpean Union. In V. Henderson and J. Thisse (eds), Handbook of Urban and Regional Economics, Volume 4. Amsterdam: North-Holland. Forthcoming.

Copus, A. (1999). A New peripherality Index for the NUTS III Regions of the European Union. ERDF/FEDER Study 98/00/27/130. European Commission.

Cowell, F. A. (1995). Measuring Inequality, 2nd Edition. London: Prentice-Hall.

Davies, J. and A. Shorrocks (1989). Optimal Grouping of Income and Wealth Data. Journal of Econometrics. 42: 97-108.

Devereux, M., R. Griffith and H. Simpson (2002). The geographic distribution of productive activity in the UK. Regional Science and Urban Economics. Forthcoming.

Dewhurst, J. and P. McCann (2003). Specialisation and Regional Size. Mimeo. University of Dundee.

Esteban, J., C. Gradín and D. Ray (1999). Extension of a Measure of Polarization with an application to the income distributions of five OECD countries. Luxembourg Income Study Working Paper Series 218. Syracuse University: Maxwell School of Citizenship and Public Affairs.

European Commission (1999). Sixth Periodic Report on the Social and Economic Situation of the Regions in the European Union. Brussels.

Fujita, M., P. Krugman and A. Venables (1999). The Spatial Economy. Cambridge: MIT Press.

Fujita, M. and J. F. Thisse (2002). Economics of Agglomeration. Cambridge: Cambridge University Press.

Fujita, M., V. Henderson, Y. Kanemoto and T. Mori (2003). Spatial distribution of economic activities in Japan and China. In V. Henderson and J. Thisse 
(eds), Handbook of Urban and Regional Economics, Volume 4. Amsterdam: NorthHolland. Forthcoming.

Gil, C., P. Pascual and M. Rapún (2002). "Structural change, infrastructure and convergence in the regions of the European Union". European Urban and Regional Studies 9: 115-135.

Greenway, D. and R. Hine (1991). Intra-industry specialisation, trade expansion and adjustment in the European economic space. Journal or Common Mardet Studies 29: 603-622.

Grubel, H. and P. Lloyd (1975). Intra-industry trade. The theory and measurement or international trade in differentiated products. London: Macmillan.

Haaland, J., H. Kind, K. Midelfart-Knarvik and J. Torstensson (1998). What determines the economic geography of Europe?. Discussion Paper 19/98. Norwegian School of Economics and Business Administration.

Hallet, M. (2002). Regional Specialisation and Concentration in the EU. In J. R. Cuadrado and M. Parellada (eds.), Regional Convergence in the European Union, Facts, Prospects and Policies. Berlin: Springer-Verlag.

HARRIS, C. (1954). The Market as a Factor in the Localization of Industry in the United States. Annals of the Association of American Geographers 64: 315-348.

Heckscher, E. (1919). The Effect of Foreign Trade on the Distribution of Income. Economisk Tidskrift 21: 1-32.

Holmes, T. and J. Stevens (2003). Spatial distribution of economic activities in North America. In V. Henderson and J. Thisse (eds), Handbook of Urban and Regional Economics, Volume 4. Amsterdam: North-Holland. Forthcoming.

Imbs, J. and R. WACZIARg (2003). Stages of Diversification. American Economic Review 93: 63-86.

Keeble, D., J. Offord and S. Walker (1988). Peripheral Regions in a Community of Twelve Member States. European Commission.

KIM, S. (1995). Expansion of Markets and the Geographic Distribution of Economic Activities: the Trends in US Regional Manufacturing Structure 1860-1987. Quarterly Journal of Economics 110: 881-908

KRUGMAN, P. (1979). Increaasing returns, monopolistic competition and international trade. Journal of International Economics 21: 173-181.

Krugman, P. (1980). Scale economies, product differentiation and the pattern of trade. American Economic Review 70: 950-959.

Krugman, P. (1981). Intraindustry Specialization and the Gains from Trade. Journal of Political Economy 89: 959-973.

Krugman, P. (1991a). Geography and Trade. Cambridge: MIT Press.

Krugman, P. (1991b). Increasing returns and economic geography. Journal of Political Economy 99: 483-499.

Krugman, P. (1995). Development, Geography and Economic Theory. Cambridge: MIT Press.

Midelfart-Knarvik, K., H. Overman, S. Redding and A. Venables (2000). The Location of European Industry. Economic Papers 142, Directorate General for Economic and Financial Affairs. European Commission.

Midelfart-Knarvik, K. and H. Overman (2002). Delocation and European integration: is structural spending justified?. Economic Policy 17: 323-359.

MolLE, W. (1996). The regional economic structure of the European Union: an analysis of long term developments. In K. Peschel (ed.): Regional Growth and Regional 
Policy Within the Framework of European Integration. Heidelberg: Physica-Verlag.

OHLin, B. (1933). Interregional and International Trade. Cambridge: Harvard University Press.

Ottaviano, G. and D. Puga (1998). Aglommeration in the global economy: A survey of the new economic geography. The World Economy 21: 707-731.

Overman, H. and Puga, D. (2002). Regional unemployment clusters. Economic Policy 34: $115-147$.

PACI, R. (1997). More Similar and Less Equal: Economic Growth in the European Regions. Weltwirtschaftliches Archiv 133: 609-634.

Paluzie E., J. Pons and D. Tirado (2001). Regional Integration and Specialisation Patterns In Spain. Regional Studies 35: 285-296.

Pons, J. and D. Tirado (2003). Especialización productiva y asimetrías en las fluctuaciones económicas de las regiones europeas. VI Encuentro de Economía Aplicada, Granada.

Puga, D. (1999). The rise and fall of regional inequalities. European Economic Review 43: 303-334.

PugA, D. (2002). European regional policies in light of recent location theories. Journal of Economic Geography 2: 373-406.

QuAH, D. (1996a). Empirics for Economic Growth and Convergence. European Economic Review 40: 1353-1375.

QuAH, D. (1996b). Regional convergence clusters across Europe. European Economic Review 40: 951-958.

QuAH, D. (1997). Empirics for Growth and Distribution: Stratification, Polarization and Convergence Clubs. Journal of Economic Growth 2: 27-59.

Ricardo, D. (1817). On the Principles of Political Economy and Taxation (edition 1971). Harmondsworth: Penguin.

Rodríguez-Pose, A. (1999). Convergence or Divergence? Types of Regional Responses to Socio-Economic Change in Western Europe. Tijdschrift voor Economische in Sociale Geografie 90: 363-378.

Sala-I-Martin, X. (1996). Regional Cohesion: Evidence and Theories of Regional Growth and Convergence. European Economic Review 40: 1325-1352.

Shuetrim, G. (1999). Gauss Routines to Estimate Univariate and Bivariate Kernel Densities. http://ideas.repec.org/c/apr/aprsft/cd0003.html.

Silverman, B. (1986). Density Estimation for Statistics and Data Analysis. Monographs on Statistics and Applied Probability 26. London: Chapman and Hall.

Terrasi, M. (2002). National and Spatial Factors in EU Regional Convergence. In J. R. Cuadrado and M. Parellada (eds.), Regional Convergence in the European Union, Facts, Prospects and Policies. Berlin: Springer-Verlag.

Theil, H. (1967). Economics and Information Theory. Amsterdam: North Holland.

Ullman, E. and Dacey, M. (1960). The Minimum Requirements Approach to the Urban Economic Base. Papers and Proceedings of the Regional Science Association 6: $174-194$. 


\section{Appendix}

The 197 territorial units considered in this paper are:

Belgium: Bruxelles-Brussel, Antwerpen, Limburg, Oost-Vlaanderen, Vlaams Brabant, West-Vlaanderen, Brabant Wallon, Hainaut, Liège, Luxembourg and Namur. Denmark. Germany: Stuttgart, Karlsruhe, Freiburg, Tübingen, Oberbayern, Niederbayern, Oberpfalz, Oberfranken, Mittelfranken, Unterfranken, Schwaben, Berlin, Bremen, Hamburg, Darmstadt, Giessen, Kassel, Braunschweig, Hannover, Lüneburg, Weser-Ems, Düsseldorf, Köln, Münster, Detmold, Arnsberg, Koblenz, Trier, Rheinhessen-Pfalz, Saarland and Sch.-Holstein. Greece: Anatoliki Makedonia, Kentriki Makedonia, Dytiki Makedonia, Thessalia, Ipeiros, Ionia Nisia, Dytiki Ellada, Sterea Ellada, Peloponnisos, Attiki, Voreio Aigaio, Notio Aigaio and Kriti. Spain: Galicia, Asturias, Cantabria, País Vasco, Navarra, La Rioja, Aragón, Madrid, Castilla-León, Castilla-la Mancha, Extremadura, Cataluña, Com. Valenciana, Baleares, Andalucía, Murcia and Canarias. France: Île de France, Champagne-Ard., Picardie, Haute-Normandie, Centre, Basse-Normandie, Bourgogne, Nord-Pas de Calais, Lorraine, Alsace, Franche-Comté, Pays de la Loire, Bretagne, Poitou-Charentes, Aquitaine, Midi-Pyrénées, Limousin, Rhône-Alpes, Auvergne, Languedoc-Rousillon, Provence-Alpes-Côte d'Azur and Corse. Ireland: Border-Midland and Western and Southern and Eastern. Italy: Valle d'Aosta, Piemonte, Liguria, Lombardia, Trentino-Alto Adige, Veneto, Friuli-Venezia Giulia, Emilia-Romagna, Toscana, Umbria, Marche, Lazio, Abruzzi, Molise, Campania, Puglia, Basilicata, Calabria, Sicilia and Sardegna. Luxembourg. Netherlands: Groningen, Friesland, Drenthe, Overijssel, Gelderland, Flevoland, Utrecht, Noord-Holland, Zuid-Holland, Zeeland, NoordBrabant and Limburg. Austria: Burgenland, Niederöster., Wien, Kärnten, Steiermark, Oberösterreich, Salzburg, Tirol and Vorarlberg. Portugal: Norte, Centro, Lisboa e Vale do Tejo, Alentejo, Algarve, Açores and Madeira. Finland: Itä-Suomi, Väli-Suomi, Pohjois-Suomi, Uusimaa, Etelä-Suomi and Aland. Sweden: Stockholm, Östra Mellansverige, Sydsverige, Norra, Mellansverige, Mellersta Norrland, Övre Norrland, Smaland med oarna and Västsverige. United Kingdom: Tees Valley and Durham, Northumberland et al., Cumbria, Cheshire, Greater Manchester, Lancashire, Merseyside, East Riding, North andorkshire, South Yorkshire, West andorkshire, Derbyshire, Leicestershire, Lincolnshire, Hereford et al., Shropshire, West Midlands, East Anglia, Bedfordshire, Essex, Inner London, Outer London, Berkshire et al., Surrey, Hampshire, Kent, Avon et al., Dorset, Cornwall, Devon, West Wales, East Wales, North East Scotland, Eastern Scotland, South West Scotland, Highlands and Islands and Northern Ireland.

[INSERT FIGURE A1 AROUND HERE]

[INSERT TABLE A1 AROUND HERE]

[INSERT TABLE A2 AROUND HERE]

[INSERT MAP A1 AROUND HERE] 
Figures and Tables

Figure 1: Regional specialization $(1977=100)$.

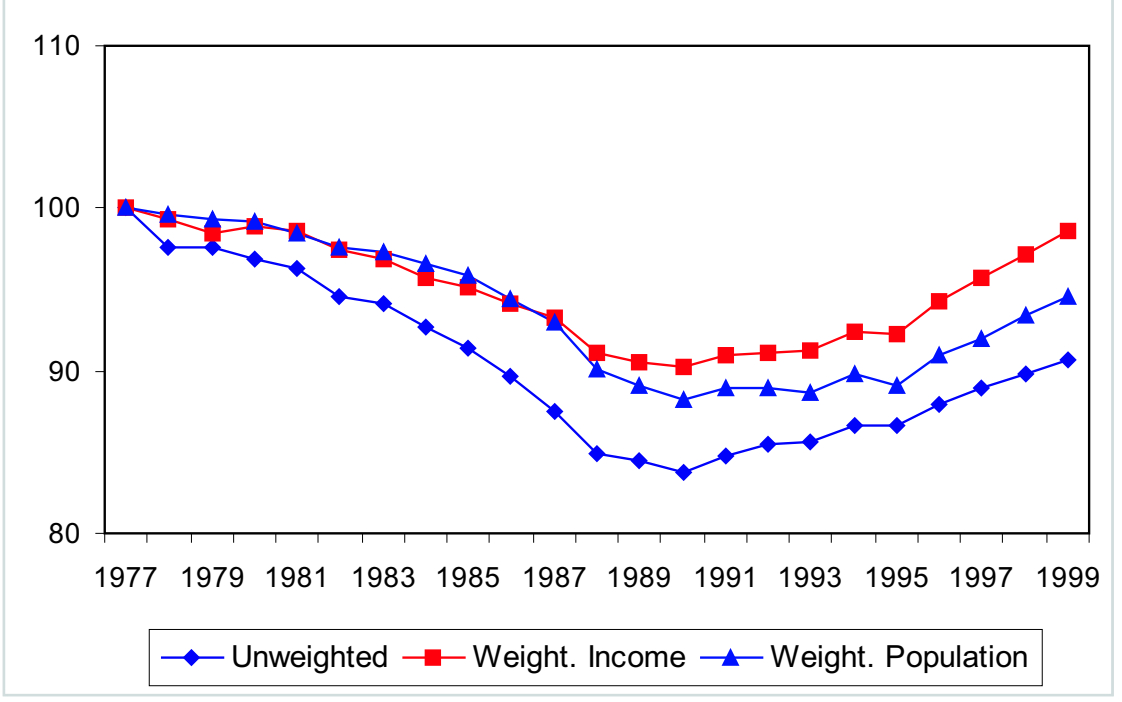


Figure 2: Convergence in regional specialization.

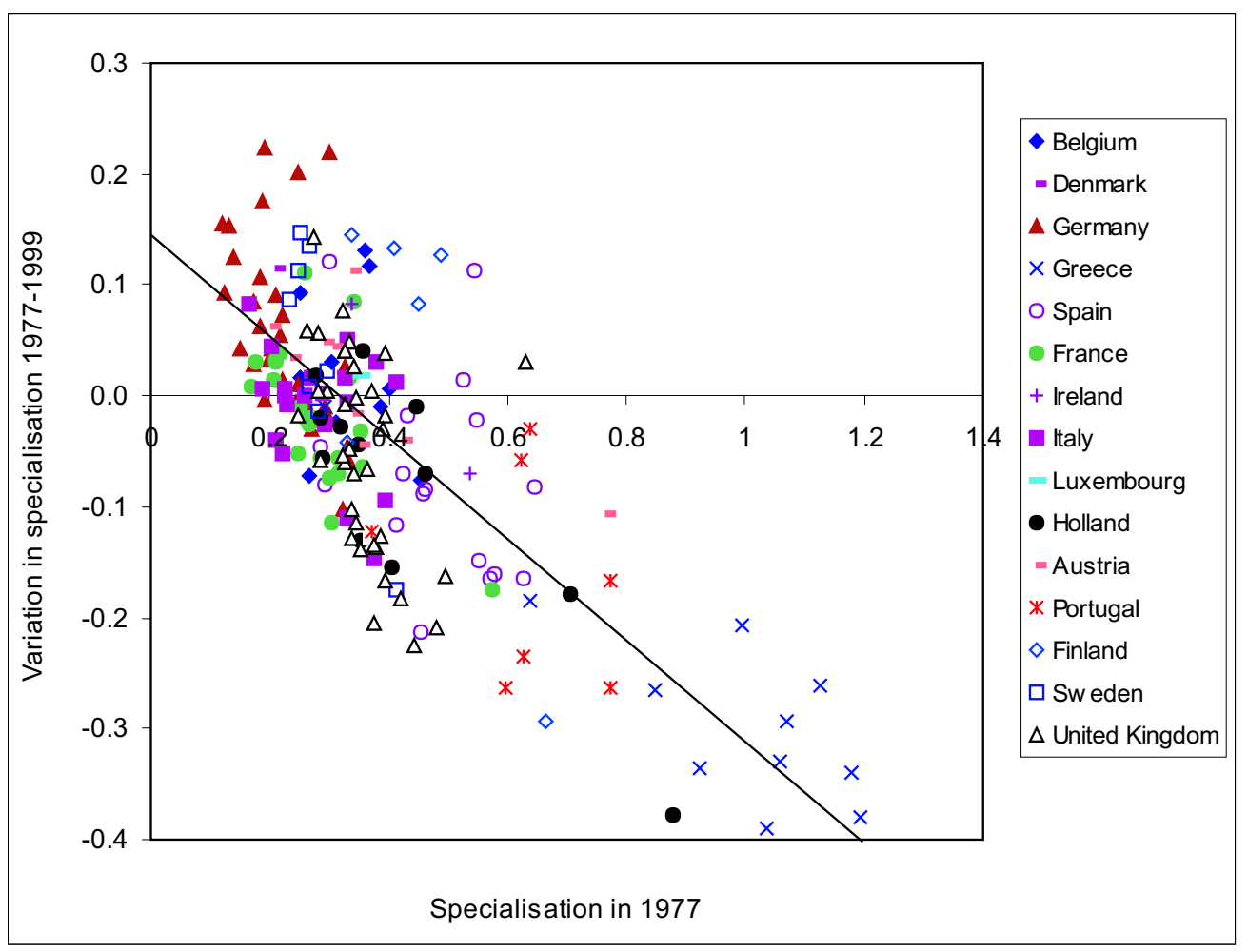


Figure 3: Density functions of the regional distribution of $S P E_{i}^{K}$.
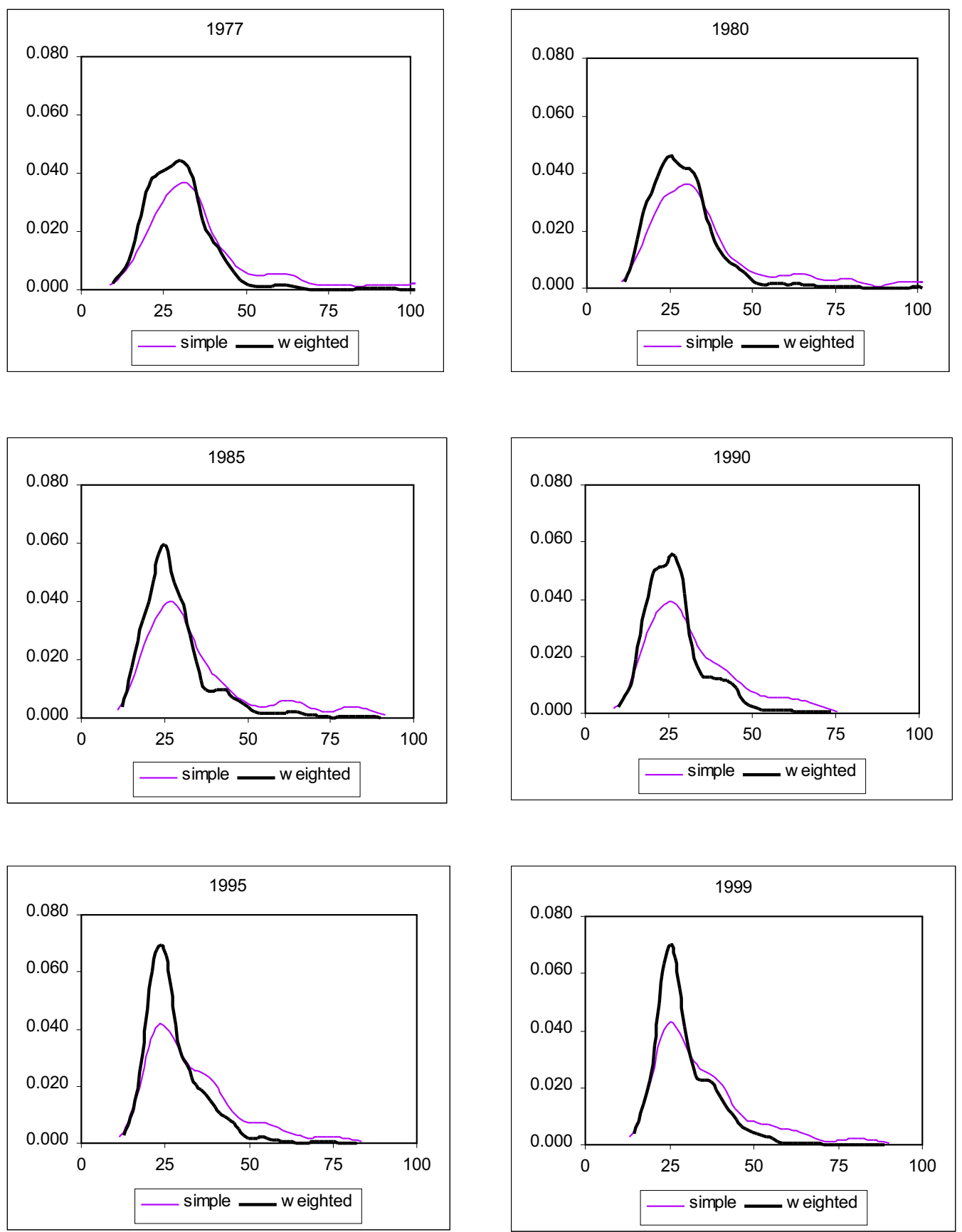
Figure 4: Stochastic kernel and contour plot of the regional distribution of $S P E_{i}^{K}$.

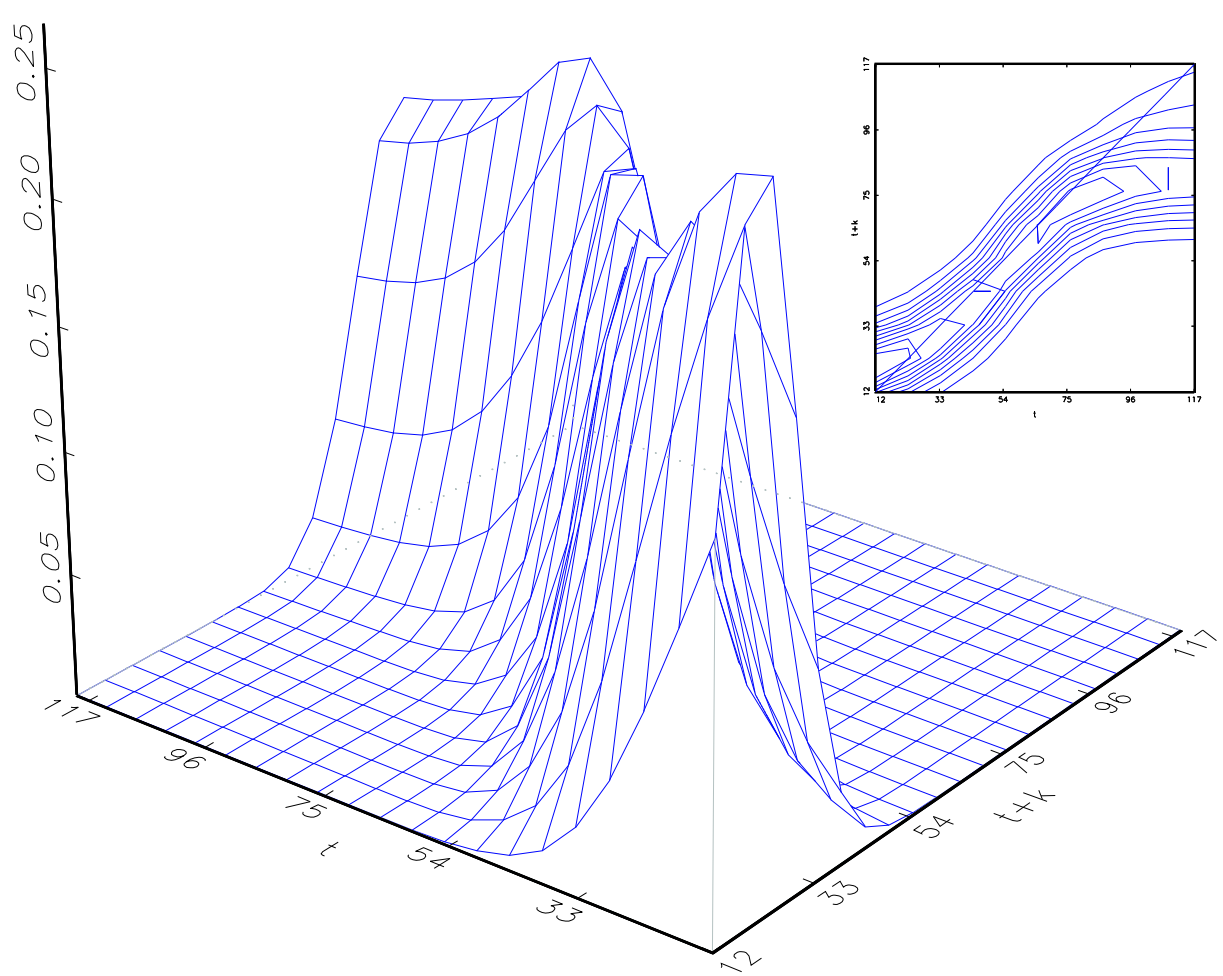

Figure 5: Ergodic distribution of the regional distribution of $S P E_{i}^{K}$.

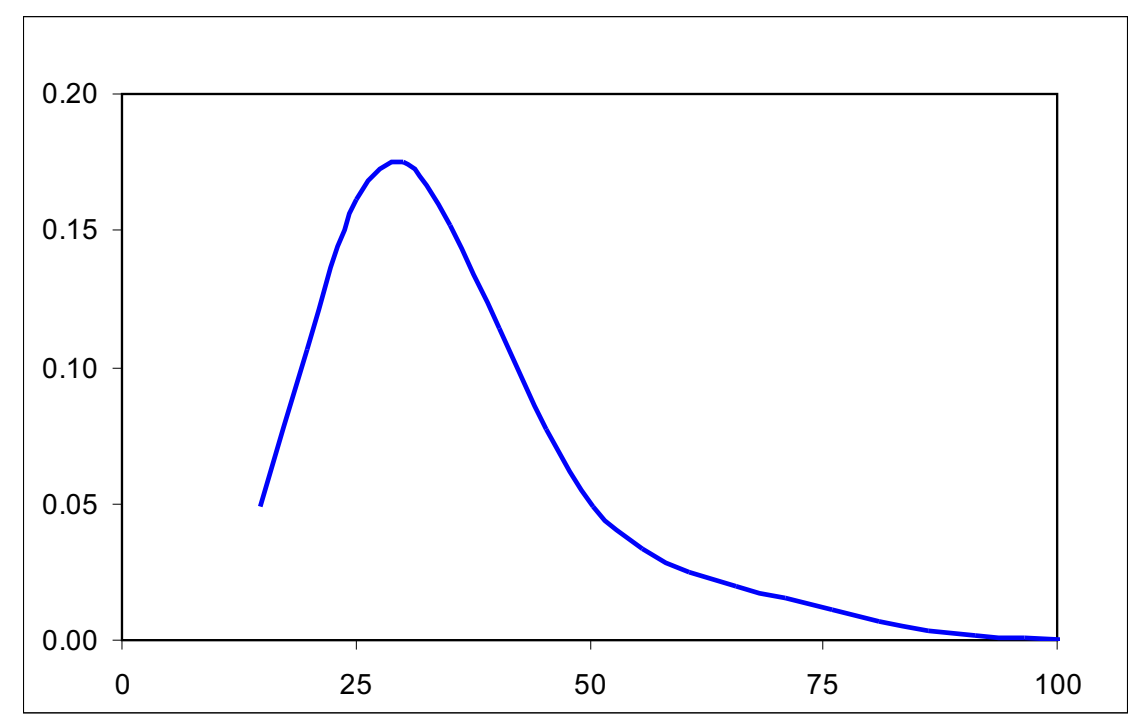


Figure 6: The spatial dimension and the distribution dynamics of $S P E_{i}^{K}$.

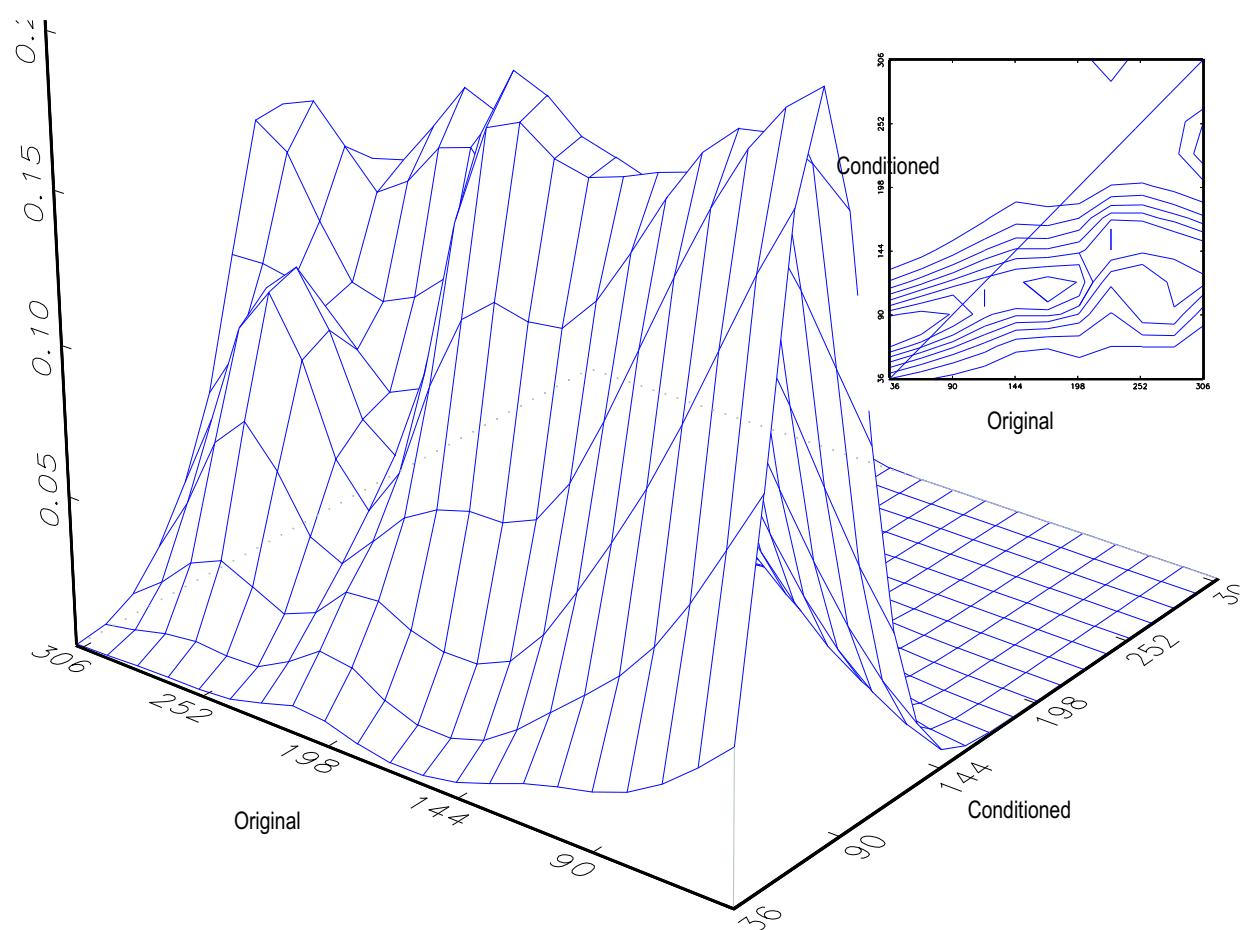

Figure A1: Regional specialization according to $S P E_{i}^{(2)} \quad(1977=100)$.

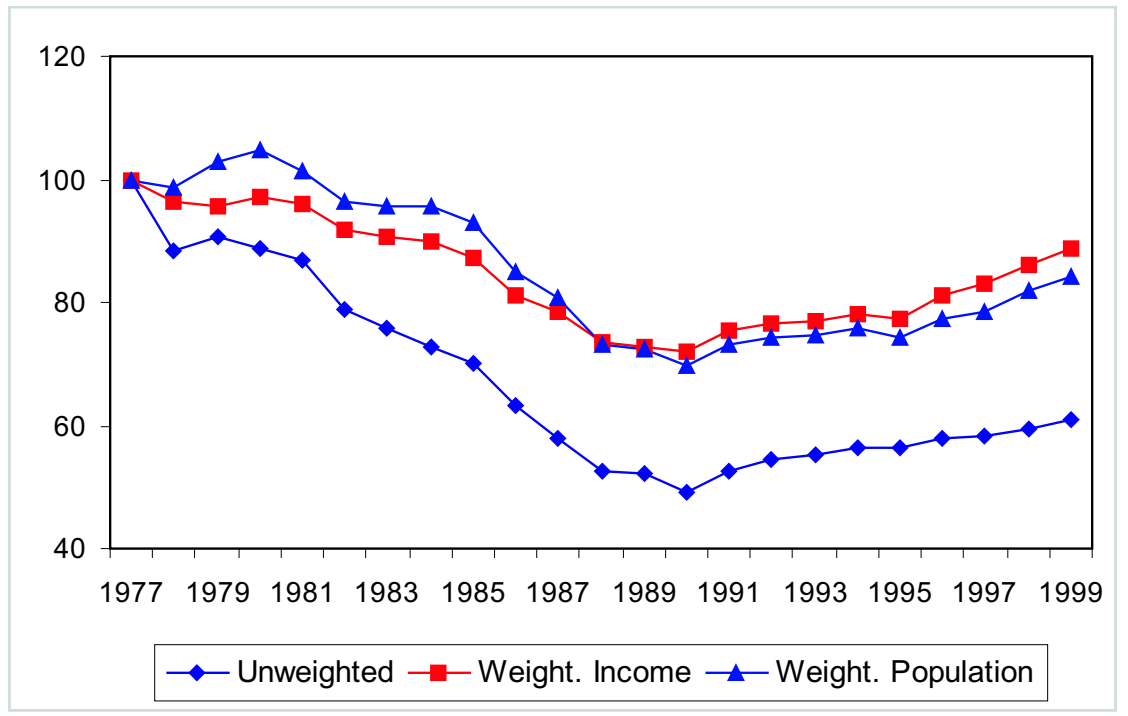


Table 1: Explanatory factors of regional specialization. (Generalized Least Squares.)

\begin{tabular}{|c|c|c|c|c|}
\hline Dependent var. & $S P E_{i t}^{K}$ & $S P E_{i t}^{K}$ & $S P E_{i t}^{(2)}$ & $S P E_{i t}^{(2)}$ \\
\hline Constant & $\begin{array}{c}12.3419^{* * *} \\
(26.094)\end{array}$ & $\begin{array}{c}10.6665^{* * *} \\
(16.774)\end{array}$ & $\begin{array}{c}2.6605^{* * *} \\
(23.466)\end{array}$ & $\begin{array}{c}1.2463^{* * *} \\
(8.443)\end{array}$ \\
\hline $\log P O P_{i t}$ & $\begin{array}{c}-0.0979^{* * *} * \\
(-20.082)\end{array}$ & $\begin{array}{c}-0.0509 * * * \\
(-9.725)\end{array}$ & $\begin{array}{c}-0.0129^{* * *} \\
(-10.999)\end{array}$ & $\begin{array}{c}-0.0047^{* * *} \\
(-3.841)\end{array}$ \\
\hline $\log D E N S_{i t}$ & $\begin{array}{c}0.0072^{\text {*** }} \\
(3.962)\end{array}$ & $\begin{array}{c}-0.0103^{* * *} \\
(-5.491)\end{array}$ & $\begin{array}{l}-0.0005 \\
(-1.040)\end{array}$ & $\begin{array}{c}-0.0034^{* * *} \\
(-7.873)\end{array}$ \\
\hline $\log G V A p c_{i t}$ & $\begin{array}{c}-2.3486^{* * *} \\
(-22.707)\end{array}$ & $\begin{array}{c}-2.1137^{* * * *} \\
(-15.469)\end{array}$ & $\begin{array}{c}-0.5312^{* * *} \\
(-21.426)\end{array}$ & $\begin{array}{c}-0.2617^{* * *} \\
(-8.253)\end{array}$ \\
\hline$(\log G V A p c)_{i t}^{2}$ & $\begin{array}{c}0.1203^{* * *} \\
(21.457)\end{array}$ & $\begin{array}{c}0.1109^{* * *} \\
(15.153)\end{array}$ & $\begin{array}{c}0.0274^{* * * *} \\
(20.397)\end{array}$ & $\begin{array}{c}0.0141^{* * *} \\
(8.317)\end{array}$ \\
\hline$C E N T R A L_{i}$ & $\begin{array}{l}-0.0032 \\
(-0.747)\end{array}$ & & $\begin{array}{l}-0.0005 \\
(-0.549)\end{array}$ & \\
\hline $\mathrm{NORTH}_{i}$ & $\begin{array}{c}0.0657^{* * *} \\
(10.938)\end{array}$ & & $\begin{array}{c}0.0035^{* *} \\
(2.467)\end{array}$ & \\
\hline $\mathrm{SOUTH}_{i}$ & $\begin{array}{c}0.0877^{* * *} \\
(15.862)\end{array}$ & & $\begin{array}{c}0.0104^{* * * *} \\
(7.867)\end{array}$ & \\
\hline National dummies & NO & YES & NO & YES \\
\hline F-Test & $764.65^{* * *}$ & $406.44^{* * *}$ & $431.67^{* * *}$ & $283.37^{* * *}$ \\
\hline $\bar{R}^{2}$ & 0.5523 & 0.6275 & 0.4103 & 0.5398 \\
\hline Observations & 4,334 & 4,334 & 4,334 & 4,334 \\
\hline
\end{tabular}

Note: Figures that appear in brackets refer to Student's t statistics. * Statistically significant at the $10 \%$ level. ${ }^{* *}$ Statistically significant at the $5 \%$ level. ${ }^{* * *}$ Statistically significant at the $1 \%$ level. Standard errors have been calculated by means of White's robust heteroscedasticity corrected covariance matrix.

Table 2: Correlation between specialization, inequality and regional polarization.

\begin{tabular}{c|ccc} 
Measures & $\begin{array}{c}E S P^{K} \\
\text { (unweighted) }\end{array}$ & $\begin{array}{c}E S P^{K} \\
\text { (weight. Income) }\end{array}$ & $\begin{array}{c}E S P^{K} \\
\text { (weight. Populat.) }\end{array}$ \\
\hline \hline$G(x)$ & $0.811^{* *}$ & $0.637^{* *}$ & $0.778^{* *}$ \\
$T(0)$ & $0.729^{* *}$ & $0.589^{* *}$ & $0.704^{* *}$ \\
$T(1)$ & $0.749^{* *}$ & $0.580^{* *}$ & $0.725^{* *}$ \\
$A(0.5)$ & $0.749^{* *}$ & $0.610^{* *}$ & $0.711^{* *}$ \\
$A(1)$ & $0.735^{* *}$ & $0.609^{* *}$ & $0.700^{* *}$ \\
$A(2)$ & $0.701^{* *}$ & $0.602^{* *}$ & $0.676^{* *}$ \\
$P(1,1)(2$ groups) & $0.846^{* *}$ & $0.638^{* *}$ & $0.816^{* *}$ \\
$P(1.6,1)(2$ groups) & $0.824^{* *}$ & $0.616^{* *}$ & $0.796^{* *}$ \\
$P(1,1)(3$ groups) & $0.929^{* *}$ & $0.776^{* *}$ & $0.905^{* *}$ \\
$P(1.6,1)$ (3 groups) & $0.953^{* *}$ & $0.815^{* *}$ & $0.936^{* *}$ \\
\hline \hline
\end{tabular}

Note: ${ }^{*}$ Statistically significant at the $5 \%$ level. ${ }^{* *}$ Statistically significant at the $1 \%$ level. 
Table A1: Sectors (NACE-CLIO R17).

\begin{tabular}{l|l}
\hline \hline Sector 1 & Agricultural, forestry and fishery products. \\
Sector 2 & Fuel and power products. \\
Sector 3 & Ferrous and non-ferrous products. \\
Sector 4 & Non-metallic minerals and mineral products. \\
Sector 5 & Chemicals products. \\
Sector 6 & Metal products and machinery. \\
Sector 7 & Transport equipment. \\
Sector 8 & Food, beverages and tobacco. \\
Sector 9 & Textiles and clothing, leather and footwear. \\
Sector 10 & Paper and printing products. \\
Sector 11 & Other manufactured products. \\
Sector 12 & Building and construction. \\
Sector 13 & Recovery, repair, trade, lodging and catering services. \\
Sector 14 & Transport and communication services. \\
Sector 15 & Services of credit and insurance institutions. \\
Sector 16 & Other market services. \\
Sector 17 & Non-market services. \\
\hline \hline
\end{tabular}

Table A2: Relationship between regional specialization and time variable (Generalized Least Squares.)

\begin{tabular}{c|c} 
Dependent variable & $S P E_{i t}^{K}$ \\
\hline \hline Constant & $0.4027^{* * *}$ \\
$T_{i t}$ & $(43.634)$ \\
& $-0.0095^{* * *}$ \\
$T_{i t}^{2}$ & $(-5.652)$ \\
& $0.0003^{* * *}$ \\
F-Test & $(4.630)$ \\
$\bar{R}^{2}$ & $23.96^{* * *}$ \\
Observations & 0.0104 \\
\hline \hline
\end{tabular}

Note: Figures that appear in brackets refer to Student's t statistics. * Statistically significant at the $10 \%$ level. ${ }^{* *}$ Statistically significant at the $5 \%$ level. ${ }^{* * *}$ Statistically significant at the $1 \%$ level. Standard errors have been calculated by means of White's robust heteroscedasticity corrected covariance matrix. 
Map A1: Geographical areas.

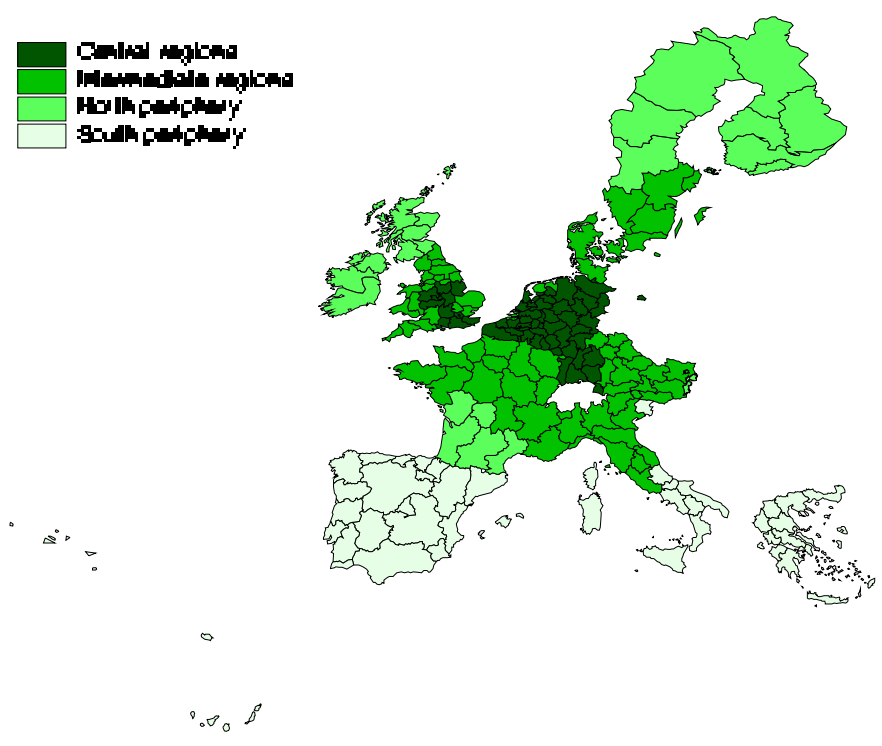

